\title{
Develop Rural Tourism in Beijing-Tianjin-Hebei Region, Promote Rural Modernization Construction
}

\author{
Liu Hong-yin \\ College of Humanities \\ Tianjin Agricultural University \\ Tianjin, P.R.China \\ lhy813@163.com
}

\author{
Zhang Wei \\ College of Humanities \\ Tianjin Agricultural University \\ Tianjin, P.R.China \\ willazhang312@163.com
}

\begin{abstract}
For the next 5-10 years, rural agrotourism will become the absolute leading growth point in tourism industry. Researching on the constraints and the implementation path of the development of rural tourism with the method of descriptive analysis. The findings show increased demand for agrotourism in Beijin-Tianjin-Hebei Region will power the economic growth, farmers' increase income; promote servicizing of agriculture industry and modernization of rural areas within the region. For all the benefits mentioned above, the lack of integrated planning and resource reassignment, lagged tourism product development, and transformation and upgrading need of industry will become the major problems that hinder development of rural tourism in the region. In the article, discussion will be made to find out solutions for these problems.
\end{abstract}

Keywords-Rural Tourism; Beijing-Tianjin-Hebei Region; Rural Modernization Construction; Agrotourism

Tourism industry is one of the most widely related industries that exert strongest driving force. "Views on the Acceleration of the Development of Tourism Industry" published by State Council of China emphasizes on the "Rural Tourism and Farmer Enrichment Project”. For the next 5-10 years, rural agrotourism will become the absolute leading growth point in tourism industry. In recent years, the demand for rural tourism by urban residents in Beijing-Tianjin-Hebei Region is in constant growing, and tourist and recreational activities, such as inter-city bicycle riding or suburb and rural vacation, have gradually become a scale. Rural agrotourism has gradually formed a new industrial development pattern that facilitates the servicizing transformation of agricultural industry and modernizing transformation of rural areas in Beijing-Tianjin-Hebei Region.

\section{RURAL TOURISM PROMOTE THE RURAL MODERNIZATION CONSTRUCTION IN BEIJING-TIANJIN-HEBEI REGION}

\section{A. Rural Tourism Increase Farmer's Income}

How to increased farmer's income is the most prominent problem in the development of agricultural and rural economy. In the year 2016, increase rate of rural resident's disposable income decline to $6.5 \%$, decline by $1.6 \%$ YoY, lower than the GDP growth rate during the same period, and is the lowest level in recent 13 years[1].The low threshold and high potential of rural tourism industry can be made use to dig more potential for operational income and release growth dividend of property income.

\section{B. Rural Tourism Promote the Growth of Rural Economy}

The data collected by Hebei Agriculture University from 5 rural tourism experimental units of Hebei Province during 2001-2011, show that $1 \%$ increase in rural tourism income can generate $0.38 \%$ increase in local economy. Prosperous rural tourism can promote the growth of rural economy[2-3]. Beijing Tianjin and Hebei are not in the same development level, even though Beijing and Tianjin develop better than Hebei Province, they are still surrounded by lots of less developed villages and farmlands. The coordinated development of the three areas brings opportunities for development of rural tourism, especially for traffic construction. To the year 2020, inter-city railway network among Beijing, Tianjin and Hebei region will be completed and will worked together with existed roadway network to connect all the cities of prefecture level and above, basically achieve the $0.5-1 \mathrm{~h}$ commuting circle among downtowns of Beijin, Tianjin and Shijiazhuang and other surrounded cities and towns; and achieve the 0.5-1h traffic circle among Beijing, Tianjin and Baoding areas[4].The traffic integration of Beijing-Tianjin-Hebei Region facilitated the coordinated development of rural tourism in these three areas.

\section{Demand for Agrotourism in Beijing-Tianjin-Hebei Region is in Sustaining Growing}

A research from World Tourism Organization shows that tourism industry become mature and step into vacation tour stage when GDP per capita reached 5000 US Dollars. Leisure demand and consumption capacity keep on growing and become diversified at this stage[5]. Till the year 2014, GDP per capita in Beijing, Tianjin and Heibei area had reached 16300 dollars, 17100 dollars, and 6500 dollars respectively, demonstrate that Beijing-Tianjin-Heibei Region has stepped into stage of vacation tour. Furthermore, Beijing and Tianjin are in transformation period toward the high-quality leisure and sightseeing tourism. Diversified leisure demand provides more opportunities for dislocation development of rural tourism in Beijing-Tianjin-Heibei Region. 


\section{THREE PROBlems FACED BY RURAL TOURISM DEVELOPMENT IN BEIJING-TIANJIN-HEBEI REGION}

\section{A. Rural Tourism Lack of Integrated Planning and Resource Reassignment}

Scale of development has not been formed in BeijingTianjin-Hebei Region due to scattered allocation of tourist resources, underdeveloped traffic network among scenic spots and uncoordinated planning of scenic spots[6].

Besides, high-quality leisure services are unable to be provided due to insufficient infrastructure, homogenized leisure service and poor accessibility.

\section{B. Lagged Development of Rural Tourism Products}

General tourist accommodation is still the main content of rural tourism. Lack of ethnic characteristics, under-utilization of folk cultural resources, indistinctive tourism projects are the major obstacles for the rural tourism to meet high-level, individualized tourist needs. Few agrotourism projects based on native, handcrafted, artistic tourist culture are provided; environmental protection concept, ecological technology and ecological landscape are not well fused together; tourism products can't meet the consumption needs of tourist from big cities like Beijing.

\section{Rural Tourism Industry Needs to Be Transformed and Upgraded}

With rapid development of economy and upgrading of consumption structure, contents of rural tourism should extend beyond primary activities like having farmhouse style meals, living in farmhouse or fruit picking and sightseeing, to include more innovative and creative elements. The consumption needs is becoming more diversified. Rural tourism in Beijing and Tianjin areas should take the lead in the transformation and upgrading process to change from sightseeing and fruit picking to experience type vacation.

\section{POLICY SUgGESTION FOR ACCELERATING STANDARDIZED DEVELOPMENT OF RURAL TOURISM IN BEIJING-TIANJIN-HEBEI REGION}

\section{A. Develop Industrial Standard, Promote Healthy Development of Rural Tourism}

Develop rural tourism standard, develop service standard for rural tourism experimental units, develop standard for tourism experimental towns (villages) or experimental region, develop service standard for agritainment and rural hotel, and regulate rural tourism to achieve a healthy and sustainable development.

Develop mid-term and long-term personnel training plan to conduct vocational training for employees (especially farmer employees) working in rural tourism industry. Standardize services to regulate rural tourism practitioners, improve taste and level of rural tourism projects.

\section{B. Develop Projects to Forester Tourism Product with Rural Characteristics}

Accelerate building of national and provincial agrotourism and rural tourism experimental town.

Enhance cooperation with tourism department; promote development of rural tourism products by introducing topquality tourism routes and regional tourism festival. Combine modern agriculture projects, rural infrastructure projects, and eco-agriculture projects with rural tourism projects, priority support and elaborate a group of attractive and characteristic rural tourism products with profound market potential.

Accelerate construction of infrastructure and supporting facilities for rural tourism, improve supporting level and integrated service function[7].

Make extensive use of coordinate development platform for rural tourism in Beijing-Tianjin-Hebei Region, regularly communicate latest trends and situation of rural tourism among different places, promote sharing of talent, information and standard, support cross-boundary and joint development.

Refine rural traffic system, prioritized building and mending of roads leaded to scenic spots when planning to build the roads to towns and villages, strive to develop tourist bus and sightseeing bus route.

\section{Reassign Fiscal Funds, Increase Financial Support for Rural Tourism}

Integrate together special funds used for agriculture, rural areas and tourism development such as tourism development and beautiful village construction funds, set up a special fund to support rural tourism, organize a rural tourism leading group to conduct unified arrangement and allocation.

Preferential policies for agriculture and beautiful village construction should be applied to rural tourism projects. Agriculture projects and rural tourism projects should be combined together to strive for policies and financial support from state government.

Put more efforts on investment promotion, encourage domestic and international financial institutions to develop investment and financing products in the field of rural tourism.

Encourage non-government capital to invest on rural tourism projects in the form of sole proprietorship, joint venture or partnership.

Encourage farmers to invest on the project with lands or take part in the rural tourism development by using their own house property, orchard or forest farm, etc.

\section{Develop Preferential Policy, Create Healthy Environment for Rural tourism}

Strengthen policy support and increase subsidy for rural tourism, develop measures of development and support, and preferential policies for rural tourism projects, refine policies and measures to promote investment, promote development of rural tourism projects. 
Optimize environment for rural tourism, simplified approval process, forester and develop intermediary organizations like rural tourism association, enhance supervision for rural tourism service.

\section{E. Strengthen Brand Construction, Expand Channels to Extend Rural Tourism}

Firstly, take rural tourism as a main product and marketing emphasis, include it into overall marketing and promotion plan, to package and sell it as a whole. Create theme tourism image and conduct accurate market orientation based on rural tourism features of different regions. Combine with market demand to conduct overall marketing for rural tourism product with different marketing measures.

Secondly, enhance publicity and presentation for the theme image of scenic spot. Extend brand publicity channel, highlight brand characteristic, and promote popularity of scenic spot. Popularize scenic spot and promote information sharing among various tourism platform through both major media and traditional tourism platform, and online tourism platform such as Microblog, Wechat and mobile APPs.

Thirdly, enhance the scenic spot building to create rural tourism brand, make use of feature of scenic spot in natural environment, culture, agriculture, national customs, folklore characteristic and historical culture to foster classic agrotourism project and to launch tourism brand with profound local characteristics such as experiencing ethnic culture, modern agriculture sightseeing, spending spring festival in rural areas, folk customs show, to attract visitors from all over the world.

\section{CONCLUSION}

Rural tourism can help to increase farmers' income and rural economic growth, and promote agricultural servitization and rural modernization of the Beijing-Tianjin-Hebei region. However, there exist such problems as the lack of unified planning and resource integration of rural tourism of BeijingTianjin-Hebei, and the lag of tourism product development, and the slow of transformation and upgrading of tourism industry. Suggesting starting with such fields as standards implementation, project development impetus, financial capital integration, and preferential policy support and brand construction, promoting the coordinated development of rural tourism of the Beijing-Tianjin-Hebei region to drive the construction of modern country.

\section{ACKNOWLEDGEMENTS}

This work was financially supported by the National Social Science Foundation (13AJY008)

\section{REFERENCES}

[1] The National Bureau of Statistics. "GDP growth by $6.7 \%$ in the first half of 2016". Information Times, July 16, 2016

[2] J. Li and J. Wang, "Analysis on the Relationship Between Rural Tourism and Rural Economic Growth". Proceedings of the Annual Meeting of China's Tourism Science, 2014, pp. 24-29.

[3] J. Li, "Study on the relationship between the rural tourism and rural economic growth". Hebei Agricultural University, 2014, pp. 21-29.

[4] N. Geng, "The Beijing-tianjin-baoding will form an-hour traffic circle". Beijing Daily, December 15, 2016

[5] K. Cui, "the Analysis and Countermeasures on the Development Mode of Beijing-tianjin-hebei Integration of Leisure Agriculture". The Research Briefing, vol.71, 2015, p. 2.

[6] A.P. Xu, "A Preliminary Study of Tianjin Agricultural Eco-tourism Development Under the Background of the Coordinated Development of Beijing-Tianjin-Hebei". Agricultural Science and Technology Management, vol.35, 2016, pp. 5-8.

[7] J. Li and G. X. Sun, "Development orientation and realization approach of Tianjin modern urban agriculture in the next five years". Research Briefing, vol. 69, 2015, p4. 